\title{
Shear tests on GFRP reinforced concrete beams
}

\author{
Damian Szczech ${ }^{1, *}$ and Renata Kotynia ${ }^{1}$ \\ ${ }^{1}$ Lodz University of Technology, Department of Concrete Structures, Al. Politechniki 6, Lodz, Poland
}

\begin{abstract}
This paper aims to investigate the shear failure mechanisms in beams reinforced with longitudinal and transverse glass fibre reinforced polymer bars. It is a part of comprehensive research on shear in concrete beams reinforced with steel and GFRP bars. The experimental program is composed of six real-scale single-span, simply-supported T-cross section concrete beams. The beams varied mainly with respect to the longitudinal reinforcement ratio $(2.91 \%$ and $3.69 \%)$, bar diameter $(25 \mathrm{~mm}$ and $28 \mathrm{~mm}$, respectively) and transverse reinforcement ratio $(0.16 \%$ and $0,33 \%)$. The paper presents test results, cracking patterns, failure modes and an analysis of the influence of variable parameters on the shear behaviour of elements.
\end{abstract}

\section{Introduction}

Fibre reinforced polymer (FRP) bars have been increasingly used as one of the main substitutes for traditional steel reinforcement, especially in reinforced concrete structures. The main reason for the increasing popularity of FRP materials is their high strength to weight ratio, corrosion resistance and neutral magnetic characteristics. The paper presents an analysis of test results performed on concrete beams reinforced with glass fibre reinforced polymer (GFRP) bars used as longitudinal and transverse reinforcement. The tests were conducted at the Department of Concrete Structures (Lodz University of Technology).

Shear is a challenging research problem due to the complex stress state caused by the combination of the shear force and bending moment existing in the support region of an RC beam. Shear mechanisms depend on the characteristics of concrete, mechanical properties of the longitudinal and shear reinforcement and the interaction between the reinforcement and concrete. Determining the shear capacity of concrete beams with transverse reinforcement becomes more complicated when the longitudinal and transverse reinforcement is made of FRP, which, unlike steel, is fully anisotropic. Most of current design guidelines for concrete FRP reinforced members (ACI 440.1R 2006, CNR-DT 203 2006, CAN/CSA S806 2010, FIB Bulletin 40) [1-4] are based on the compression field theory, which assumes that the total shear strength is the sum of concrete $\left(\mathrm{V}_{\mathrm{c}}\right)$ and transverse reinforcement $\left(\mathrm{V}_{\mathrm{f}}\right)$ contribution. In fact, the increase in the transverse reinforcement ratio results in an increase in both contributions of ultimate shear resistance it increases both the contribution of the transverse reinforcement itself and the contribution

\footnotetext{
* Corresponding author: damian.szczech@p.lodz.pl
} 
of concrete through a greater confinement of the concrete section by stirrups (confined concrete).

The concrete contribution is generally determined based on beams without shear reinforcement, while the contribution of shear reinforcement is determined by using the truss theory. The contribution of concrete is influenced by many factors: compressive strength $\left(f_{c}\right)$, beam cross section $(b, h)$, the relationship between shear force and bending moment in the specified section $(\mathrm{M} / \mathrm{V})$, flexural reinforcement ratio $\left(\rho_{\mathrm{l}}\right)$, elasticity modulus of the FRP ( $\left.E_{F R P}\right)$ and sometimes the maximum aggregate diameter $\left(\mathrm{d}_{\mathrm{g}, \max }\right)$ [5-8]. The contribution of concrete to shear strength rises with an increase in the stiffness of the longitudinal reinforcement $[7,12]$. The research on normal and high strength concrete confirmed that the shear capacity increased with an increase in the compressive concrete strength. The increase from $25 \mathrm{MPa}$ to $70 \mathrm{MPa}$ indicated a shear strength increase of $104 \%$ [10]. The insignificant effect of longitudinal reinforcement ratio on the shear capacity was confirmed in the beams with transverse reinforcement. However, with the increase in the longitudinal reinforcement ratio, there was a decrease in the crack depth and the crack width. Four times lower elasticity modulus of FRP shear reinforcement compared to steel resulted in lower shear strength. The following parameters influence the contribution of the shear reinforcement: cross-section of the FRP shear reinforcement $\left(A_{w}\right)$, bar diameter $\left(\varnothing_{w}\right)$, stirrup spacing $\left(\mathrm{s}_{\mathrm{w}}\right)$, tensile strength of FRP bars $\left(\mathrm{f}_{\mathrm{FRP}}\right)$, ultimate strains $\left(\varepsilon_{\text {lim }}\right)$, elasticity modulus ( $\left.E_{F R P}\right)$, the strength of the bent FRP stirrup ( $\left.f_{\text {bend }}\right)$ and the internal radius of the bent stirrup $\left(\mathrm{r}_{\mathrm{w}}\right)[7,11]$.

The effect of the transverse reinforcement ratio on the shear strength of FRP RC beams was indicated in previous studies $[7,8,10]$. The ultimate shear strength increased with a decrease in the stirrup spacing. Higher stirrup stiffness resulted in lower average strain at the ultimate shear capacity. The radius of the bent bar corner was an important factor which influenced the shear strength of the FRP reinforced beams. The shear strength of a bent corner radius of $5 \mathrm{~mm}$ was lower than the shear strength of a bent corner radius of $10 \mathrm{~mm}$ [11]. The shear span to effective depth ratio $\mathrm{a} / \mathrm{d}$ is another parameter that significantly influences shear strength [7]. In slender beams (with a/d > 3), the arch effect did not affect the shear strength of the beams.

Due to the complexity of shear mechanisms, which are not clearly described for FRP reinforced concrete elements, the topic of the paper is very relevant and requires extensive research. The existing studies have used different types of transverse and longitudinal reinforcement as well as different shapes of the stirrups with various surface treatments of the bars. Hence, the objective of this paper is to extensively examine the influence of several parameters on the shear strength of GFRP reinforced beams. The experimental test discussed in this paper is a part of an extensive research programme and focuses on the analysis of influence of the transverse $\left(\rho_{\mathrm{w}}\right)$ and longitudinal $\left(\rho_{\mathrm{l}}\right)$ reinforcement ratio on the shear capacity of GFRP reinforced concrete beams.

\section{Experimental program}

\subsection{Test specimens}

The presented test results contain a part of an extensive research program consisting of 22 beams. The paper presents the results of tests performed on five beams with various variable parameters affecting the value of shear strength. The longitudinal reinforcement consisted of 5 GFRP bars of $25 \mathrm{~mm}$ diameter $\left(\rho_{1}=2.91 \%\right)$ and 5 GFRP bars of $28 \mathrm{~mm}$ diameter $\left(\rho_{1}=3.69 \%\right)$. The transverse reinforcement in the investigated shear span was applied in the form of closed GFRP stirrups with $8 \mathrm{~mm}$ diameter at three different spacings: 
$250 \mathrm{~mm}$ and $120 / 270 \mathrm{~mm}$, corresponding to the transverse reinforcement ratio ( $\rho_{\mathrm{w}}$ ) equal to $0.16 \%$ and $0.33 \%$, respectively. In order to investigate the impact of the diameter of GFRP stirrups and their spacing, two bar diameters $(8 \mathrm{~mm}$ and $12 \mathrm{~mm})$ and three spacings $(120$ $\mathrm{mm}, 250 \mathrm{~mm}, 270 \mathrm{~mm})$ were applied for two reinforcement ratios $\left(\rho_{\mathrm{w}}=0.16 \%\right.$ and $\left.0.33 \%\right)$. In order to investigate the influence of GFRP stirrups on shear capacity, one beam was tested without the transverse reinforcement.

The details of variable parameters analysed in the research are summarized in Table 1 $\left(\rho_{\mathrm{l}}-\right.$ flexural reinforcement ratio; $\rho_{\mathrm{w}}-$ shear reinforcement ratio; $\emptyset_{\mathrm{w}}-$ stirrup diameter; $\mathrm{s}-$ stirrup spacing). The nomenclature of beams consists of TG-k $\emptyset_{1}-\emptyset_{\mathrm{w}} / \mathrm{s}$, where: $\mathrm{T}-\mathrm{T}$-section; $\mathrm{G}$ - GFRP reinforcement; $\mathrm{k}$ - number of longitudinal bars; $\emptyset_{1}$ - longitudinal bar diameter: 25/28 mm; $\emptyset_{\mathrm{w}}-$ stirrup diameter, $8 \mathrm{~mm} ; \mathrm{s}$ - stirrup spacing $(120,250$ and $270 \mathrm{~mm}) ; \mathrm{N}-$ beam without stirrups.

Table 1. Variable parameters of analysed beams.

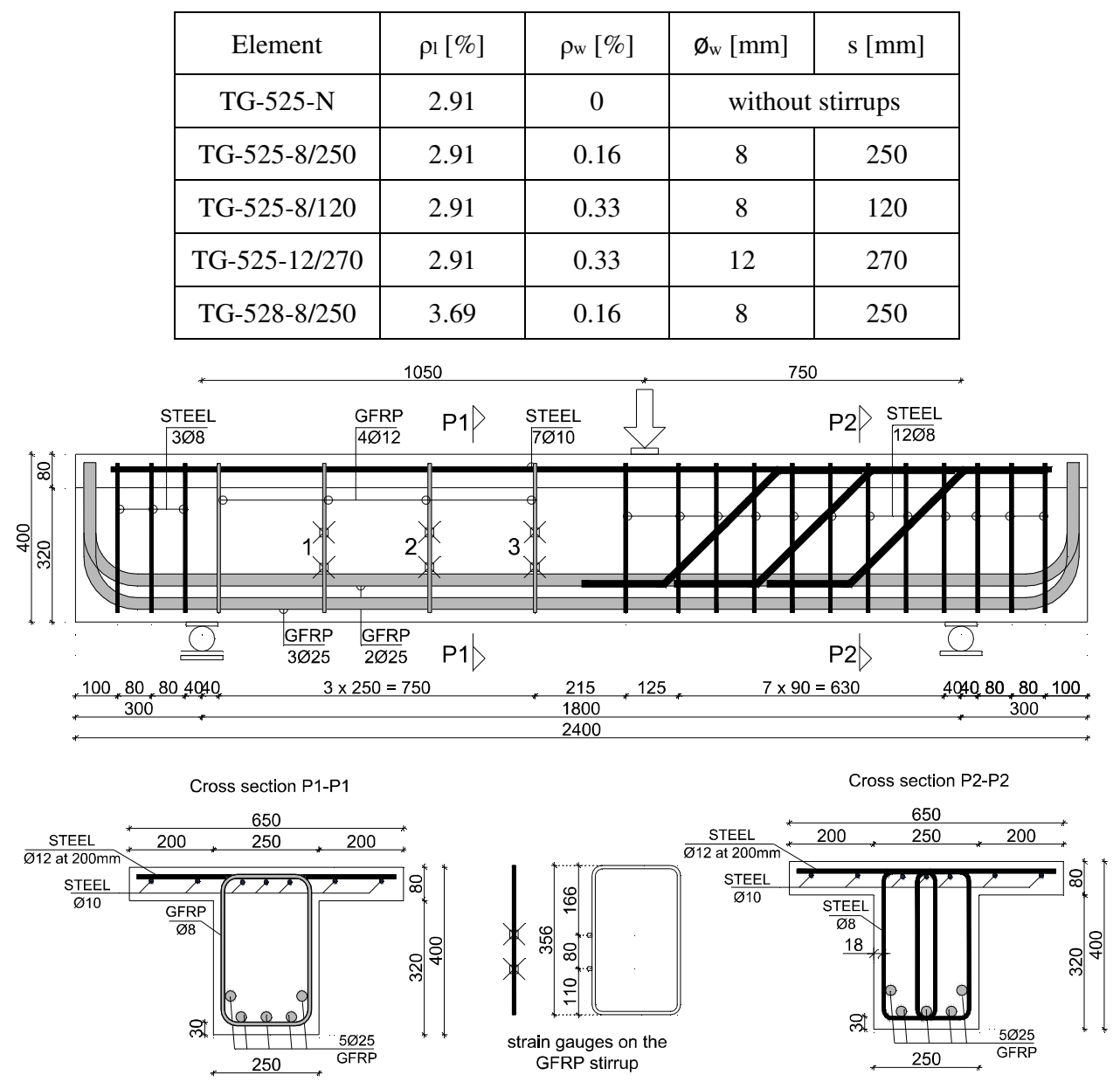

Fig. 1. Geometry of beam. GFRP and steel reinforcement.

The program included single-span simply-supported T-section beams $\left(b_{\text {eff }}=650 \mathrm{~mm}, \mathrm{~b}_{\mathrm{w}}=\right.$ $250 \mathrm{~mm}, \mathrm{~h}_{\mathrm{f}}=80 \mathrm{~mm}, \mathrm{~h}_{\text {tot }}=400 \mathrm{~mm}$ ) with an axis span of $1800 \mathrm{~mm}$. The beams were tested in a three-point loaded static scheme with a shear span-to-depth ratio (a/d) equal to 3.15 (slender beams), which prevented the arch effect. The load was located at $1050 \mathrm{~mm}$ from the support, that is in the tested shear region of the beam. It should be emphasized that only 
one shear region (close to the left support) was tested. In order to avoid shear failure on the opposite support region of the beam, strong steel reinforcement was applied (stirrups and diagonal bent bars). The static scheme with details of geometry and reinforcement is shown in Figure 1.

\subsection{Material characteristics}

Both types of reinforcement (stirrups and longitudinal bars) were made of GFRP bars with single braid ribs. The strength characteristics of the GFRP and steel reinforcement (yield strength $\mathrm{f}_{\text {yield }}$ in the case of steel bars, ultimate strength $\mathrm{f}_{\text {ult }}$ and secant modulus of elasticity E) are shown in Table 2. The steel reinforcement was made of steel B500A class.

Table 2. Mechanical properties of GFRP and steel bars.

\begin{tabular}{|c|c|c|c|c|}
\hline \multirow{4}{*}{ Bar type } & $\emptyset_{\mathrm{w}}[\mathrm{mm}]$ & $f_{\text {yield }}[\mathrm{MPa}]$ & $\mathrm{f}_{\text {ult }}[\mathrm{MPa}]$ & $\mathrm{E}[\mathrm{GPa}]$ \\
\hline \multirow{4}{*}{ GFRP bars } & 8 & - & 1529 & 79 \\
\cline { 2 - 5 } & 12 & - & 1445 & 73 \\
\cline { 2 - 5 } & 25 & - & $>1000$ & $>60$ \\
\cline { 2 - 5 } & 28 & - & 722 & 198 \\
\hline \multirow{3}{*}{ Steel bars } & 8 & 609 & 681 & 199 \\
\cline { 2 - 5 } & 12 & 532 & 690 & 196 \\
\hline
\end{tabular}

Beams were made of ready-mixed concrete consisting of: sand, crushed stone aggregate (grain diameter of $8 \mathrm{~mm}$ ), water, CEM I 52.5 Rudniki and plasticizer. The average values of compressive strength (cylinder - $f_{c, \text { cyl }}$; cubic $-f_{c, \text { cube }}$ ), tensile concrete strength $\left(f_{c t}\right)$ and its elasticity modulus $\left(\mathrm{E}_{\mathrm{c}}\right)$ are presented in Table 3 .

Table 3. Strength characteristics of concrete.

\begin{tabular}{|c|c|c|c|c|c|}
\hline Element & $\begin{array}{c}\text { age } \\
{[\text { days }]}\end{array}$ & $\begin{array}{c}\mathrm{f}_{\mathrm{c}, \text { cube }}(\sigma) \\
{[\mathrm{MPa}]}\end{array}$ & $\begin{array}{c}\mathrm{f}_{\mathrm{c}, \text { cyl }}(\sigma) \\
{[\mathrm{MPa}]}\end{array}$ & $\begin{array}{c}\mathrm{f}_{\mathrm{c}, \mathrm{ct}}(\sigma) \\
{[\mathrm{MPa}]}\end{array}$ & $\begin{array}{c}\mathrm{E}_{\mathrm{c}}(\sigma) \\
{[\mathrm{MPa}]}\end{array}$ \\
\hline TG-525-8/250 & 68 & $47.7(0.4)$ & $39.4(1.8)$ & $3.7(0.1)$ & $31.0(0.7)$ \\
\hline TG-525-8/120 & 104 & $48.7(3.6)$ & $39.0(1.1)$ & $3.6(0.1)$ & $28.8(0.4)$ \\
\hline TG-525-12/270 & 132 & $49.8(2.6)$ & $39.4(1.9)$ & $3.7(0.3)$ & $31.6(1.0)$ \\
\hline TG-525-N & 62 & $42.5(2.4)$ & $39.8(1.4)$ & $3.4(0.3)$ & $31.6(0.7)$ \\
\hline TG-528-8/250 & 71 & $47.7(0.4)$ & $39.4(1.8)$ & $3.7(0.1)$ & $31.0(0.7)$ \\
\hline
\end{tabular}

\subsection{Measurements and test setup}

The beams were tested in a test setup composed of a steel frame structure, a hydraulic jack attached to the upper part of the frame, steel hinged supports (one movable in the tested shear region) and measurement stand system SAD 256. The load was transferred via a steel cross-beam across the full width of the flange. The beam was loaded gradually until failure. 
The measuring device consisted of several linear variable differential transducers (LVDT) and strain gauges. Sensors were located in the top and bottom zones to measure concrete deformations. The LVDT gauges were installed in triangular rosettes placed in the middle of the beam height. For deflection measurements, the LVDTs were applied along the entire length of the beams (Fig. 2). Additional strain gauges were installed on the longitudinal reinforcement and GFRP stirrups (Fig. 1).

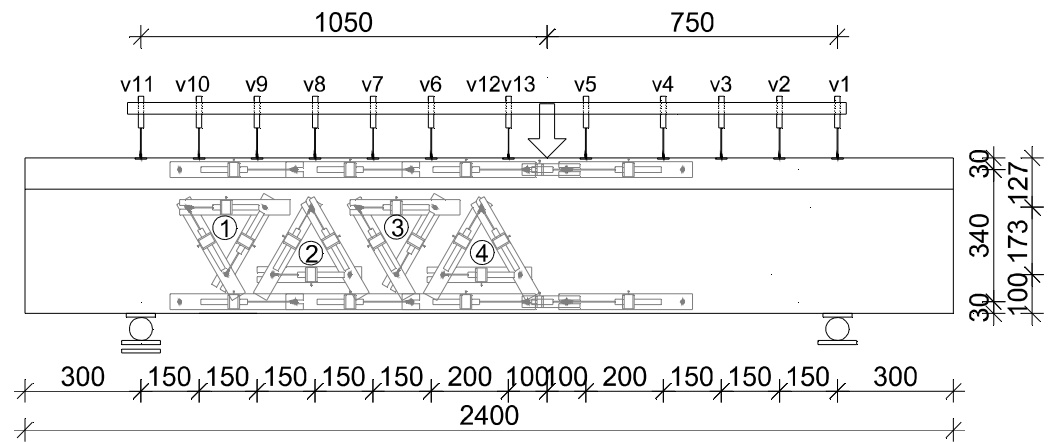

Fig. 2. Location of LVDT gauges.

\section{Experimental observations and analysis of test results}

\subsection{Cracking observation and failure modes}

All beams indicated shear failure in the tested left support region. The rupture of the stirrups or the loss of bond between the GFRP bars and concrete were not observed.

In beam TG-525-N without stirrups, after reaching the flexural cracking force $\mathrm{F}_{\mathrm{cr}, \mathrm{f}}$, only a few small primary bending cracks appeared and only one shear crack caused failure, whereas in the beams with GFRP stirrups, the crack pattern was more complex and typical for beams with shear reinforcement. The critical shear crack in beam TG-525-N started to form from the bottom edge of the beam and propagated diagonally upwards the flange with the load increase. After the critical crack reached the flange, it developed horizontally underneath until, in the final stage, it went through the flange and reached the load point. The crack development demonstrated that when passing through the second layer of the longitudinal reinforcement, the crack changed inclination to a more vertical one.

Additional diagonal cracks appeared in the beams with the GFRP shear reinforcement. In the GFRP reinforced beams, the first cracks initially occurred with almost vertical arrangement (under the flexural cracking $\mathrm{F}_{\mathrm{cr}, \mathrm{f}}$ ). These primary flexural cracks developed in the stirrup locations. Afterwards, small cracks developed as secondary bending cracks located between two adjacent primary cracks. These secondary cracks developed as slanted cracks until they joined in with the primary cracks and then, as one connected crack, propagated towards the flange as the inclined cracks.

After the initial flexural cracking (under the load $F_{c r, s}$ ), the shear cracks were formed in the centre of the beam height. These diagonal cracks developed both in the direction of the longitudinal tensile reinforcement and the upper compressive zone of the beam. Simultaneously, the primary bending cracks started to close once the width of the critical shear crack reached $0.15 \mathrm{~mm}$. As the load increased, the shear crack cut the flange and developed towards the load point leading to shear failure.

In the case of the beams with GFRP stirrups, higher transverse reinforcement ratio resulted in the formation of additional diagonal shear cracks. All diagonal shear cracks 
increased their opening width evenly. After reaching about $90 \%$ of the ultimate load $\left(\mathrm{F}_{\mathrm{ult}}\right)$, one of the diagonal shear cracks became a critical crack from the support to the loading point.

The final crack patterns of the selected beams are presented in Figures 3-4. Higher transverse reinforcement ratio caused more intensive shear cracking, yet it reduced the width of the cracks. However, in the case of beam TG-525-12/270, despite higher transverse reinforcement ratio $\left(\rho_{\mathrm{w}}=0.33 \%\right)$, large stirrup spacing $(270 \mathrm{~mm})$ with a larger diameter $(8 \mathrm{~mm})$ reduced the number of cracks, and the crack pattern of the beam was similar to that of the beam with a lower transverse reinforcement ratio $\rho_{\mathrm{w}}=0.16 \%$ (TG$525-8 / 250)$. In the beams with higher longitudinal reinforcement ratio, the shear cracks branched off near the bottom edge of the beam. In all beams, the slope of the crack passing through the flange was more horizontal than in the web of the beam.
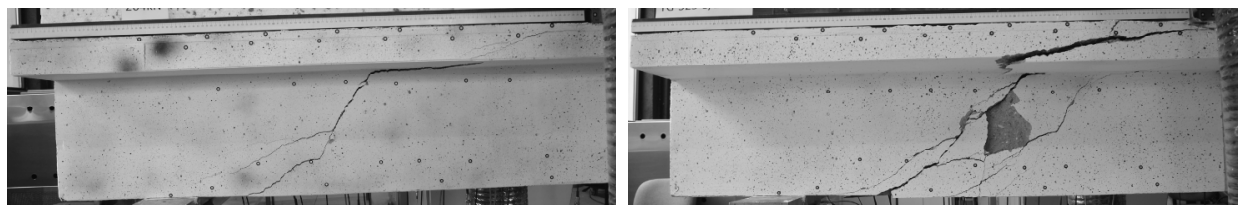

Fig. 3. Failure mode of beam TG-525-N (on the left) and TG-525-8/250 (on the right).
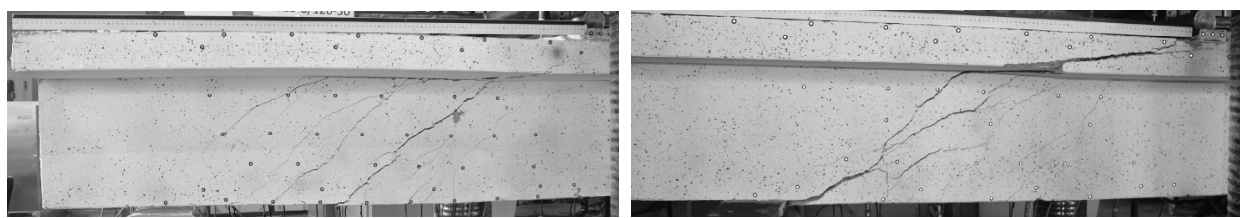

Fig. 4. Failure mode of beam TG-525-8/120 (on the left) and TG-525-12/270 (on the right).

The location of the crack, described as the distance from the beginning of the critical crack to the support $\left(\mathrm{s}_{\mathrm{cr}}\right)$, and the critical shear crack inclination $\left(\alpha_{\mathrm{cr}}\right)$ changed in the beams depending on the transverse reinforcement ratio (Table 4). The higher the transverse reinforcement ratio is, the further from the support the shear crack is located. The beams with shear reinforcement indicated a fairly similar critical shear crack inclination. However, the increase in the angle of the cracks was noticeable. A significant difference in the failure mode was observed in the beam without transverse reinforcement (TG-525-N). The inclination angle of the shear crack was much higher than in the beams with stirrups. The smaller the crack inclination, the longer its horizontal projection, and the closer the end of the crack was from the load point in the compressive zone. The increase in the transverse reinforcement ratio caused a significant reduction in the width of the critical shear crack opening for the chosen load level.

Table 4. Failure crack details.

\begin{tabular}{|c|c|c|c|c|c|c|c|}
\hline Element & $\rho_{\mathrm{w}}[\%]$ & $\mathrm{F}_{\mathrm{cr}, \mathrm{f}}[\mathrm{kN}]$ & $\mathrm{F}_{\mathrm{cr}, \mathrm{s}}[\mathrm{kN}]$ & $\mathrm{V}_{\mathrm{cr}, \mathrm{s}}[\mathrm{kN}]$ & $F_{\text {ult }}[\mathrm{kN}]$ & $\mathrm{V}_{\text {ult }}[\mathrm{kN}]$ & $\mu[-]$ \\
\hline TG-525-N & 0 & 69 & 165 & 69 & 262 & 109 & - \\
\hline TG-525-8/250 & 0.16 & 65 & 200 & 86 & 450 & 188 & 1.72 \\
\hline TG-525-8/120 & 0.33 & 70 & 250 & 104 & 780 & 325 & 2.98 \\
\hline TG-528-8/250 & 0.16 & 60 & 180 & 75 & 600 & 250 & 2.19 \\
\hline
\end{tabular}




\subsection{Experimental results}

The test results are summarized in Table 4. Based on the observation of the beams and the tensile concrete strain measurements, all tested beams confirmed flexural cracking under the load of $F_{c r, f}=60-70 \mathrm{kN}$. Diagonal shear cracking was significantly affected by the transverse reinforcement ratio. The increase in the shear reinforcement ratio caused an increase in the shear cracking load $\left(\mathrm{F}_{\mathrm{cr}, \mathrm{s}}\right)$ and the strength of the beams $\left(\mathrm{V}_{\mathrm{ult}}\right)$, which corresponds to the ultimate load $\left(\mathrm{F}_{\mathrm{ult}}\right)$. All beams with a higher longitudinal reinforcement ratio were observed to produce the first diagonal shear cracks with a lower load than beams with a lower longitudinal reinforcement ratio. However, for a beam with an increased stirrup spacing TG-525-12/270 (with the transverse reinforcement ratio retained), shear cracks appeared under a lower load than in beam TG-525-8/120. The shear forces $\left(\mathrm{V}_{\mathrm{i}}\right)$ corresponding to flexural cracking $\left(\mathrm{F}_{\mathrm{cr}, \mathrm{f}}\right)$, shear cracking $\left(\mathrm{F}_{\mathrm{cr}, \mathrm{s}}\right)$ and the ultimate load $\left(\mathrm{F}_{\mathrm{ult}}\right)$, are presented in Table 5.

Table 5. Test results.

\begin{tabular}{|c|c|c|c|c|c|c|c|c|}
\hline Element & $\begin{array}{c}\mathrm{u}_{\max } \\
{[\mathrm{mm}]}\end{array}$ & $\begin{array}{c}\mathrm{S}_{\mathrm{cr}} \\
{[\mathrm{mm}]}\end{array}$ & $\begin{array}{c}\alpha_{\mathrm{cr}} \\
{\left[{ }^{\circ}\right]}\end{array}$ & $240 \mathrm{kN}$ & $260 \mathrm{kN}$ & $300 \mathrm{kN}$ & $340 \mathrm{kN}$ & $420 \mathrm{kN}$ \\
\hline TG-525-N & 3.7 & 230 & 55 & - & - & - & - & - \\
\hline TG-525-8/250 & 10.0 & 270 & 41 & 0.25 & 0.40 & - & - & - \\
\hline TG-525-8/120 & 6.6 & 400 & 38 & 0.10 & 0.20 & 0.30 & 0.40 & 0,60 \\
\hline TG-528-8/250 & 8.5 & 170 & 36 & 0.20 & 0.35 & 0.70 & - & - \\
\hline
\end{tabular}

The increase in the shear reinforcement ratio caused an increase in the shear capacity. The increase in the shear capacity ratio of the shear reinforced beams $\left(\mathrm{V}_{\mathrm{ult}}\right)$ compared to the beam without shear reinforcement $\left(\mathrm{V}_{\mathrm{ult}, \mathrm{N}}\right)$ (parameter $\left.\mu=\mathrm{V}_{\mathrm{ult}} / \mathrm{V}_{\mathrm{ult}, \mathrm{N}}\right)$ shown in Table 4 determines the effect of the transverse reinforcement ratio on the shear strength increase. In the beam with $2.91 \%$ longitudinal reinforcement ratio, the application of the transverse reinforcement equal to $0.16 \%$ caused an increase of the shear capacity by $72 \%$ compared to the beam without the shear reinforcement. Reduction in the stirrup spacing from $250 \mathrm{~mm}$ to $120 \mathrm{~mm}$ caused an increase in the shear strength by $73 \%$, which indicates a $198 \%$ increase in the ultimate load of the beam (TG-525-8/120) compared to the beam without transverse reinforcement (TG-525-N). In the case of beam TG-525-12/270 with the same transverse reinforcement ratio $\left(\rho_{\mathrm{w}}=0.33 \%\right)$, the adoption of a small spacing of shear reinforcement $(270 \mathrm{~mm})$ caused an increase of the ultimate shear capacity by $156 \%$ compared to the beam without the shear reinforcement. The shear capacity of the beam TG-525-12/270 was 14\% lower than that of beam TG-525-8/120, which clearly shows the negative impact of a larger $270 \mathrm{~mm}$ stirrup spacing with a larger $12 \mathrm{~mm}$ stirrup diameter compared to using a smaller $120 \mathrm{~mm}$ stirrup spacing with an $8 \mathrm{~mm}$ diameter, even with the same transverse reinforcement ratio. In the case of beam TG-528-8/250, with higher longitudinal reinforcement ratio, the application of the transverse reinforcement equal to $0.16 \%$ caused an increase of the shear capacity by $112 \%$ compared to the beam without the shear reinforcement. It was $40 \%$ more than for beam TG-525-8/250, which proves that the increase in the longitudinal reinforcement ratio caused an increase in the shear capacity.

Figure 5 presents the horizonal compressive and tensile concrete strain of the tested beams under the load introduction point. The maximum compressive concrete strain did not exceed the value of 0.020 . The concrete compressive failure was not observed in the tested beams. 


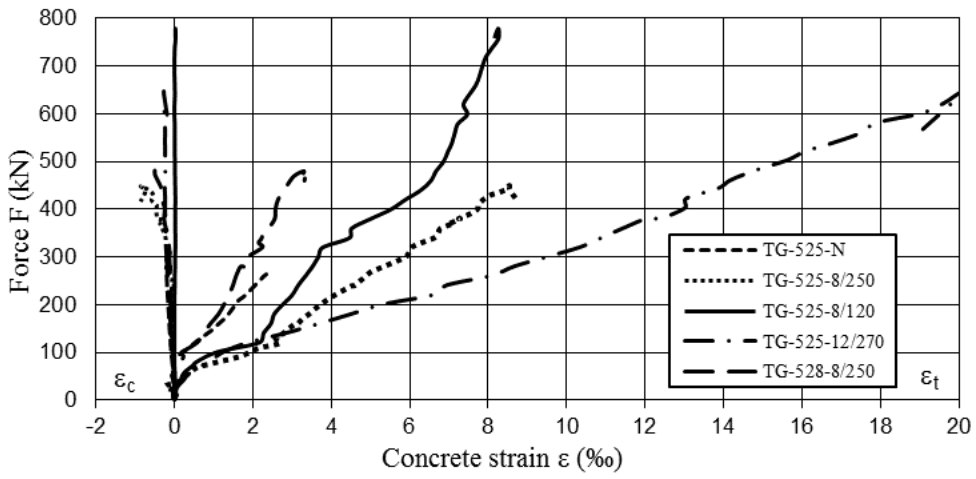

Fig. 5. Tensile and compressive concrete strain, under the load introduction point.

Figure 6 shows the principal tensile concrete strain $\varepsilon_{\mathrm{t}}$ and compressive concrete strain $\varepsilon_{\mathrm{c}}$ measured by four rosettes crossed by the critical shear cracks (rosette no. 2 and rosette no 3 , marked in Figures 2). With the increase in the transverse reinforcement ratio, the stiffness of the beams increases, which is confirmed by the inclination of principal concrete strain curves.

The biggest difference in the beam deformability is visible between the beams with and without the shear reinforcement. The difference in strain between beams TG-525-8/250 and TG-528-8/250 is negligible, although higher maximum strain values can be observed for the beam with higher longitudinal reinforcement ratio.
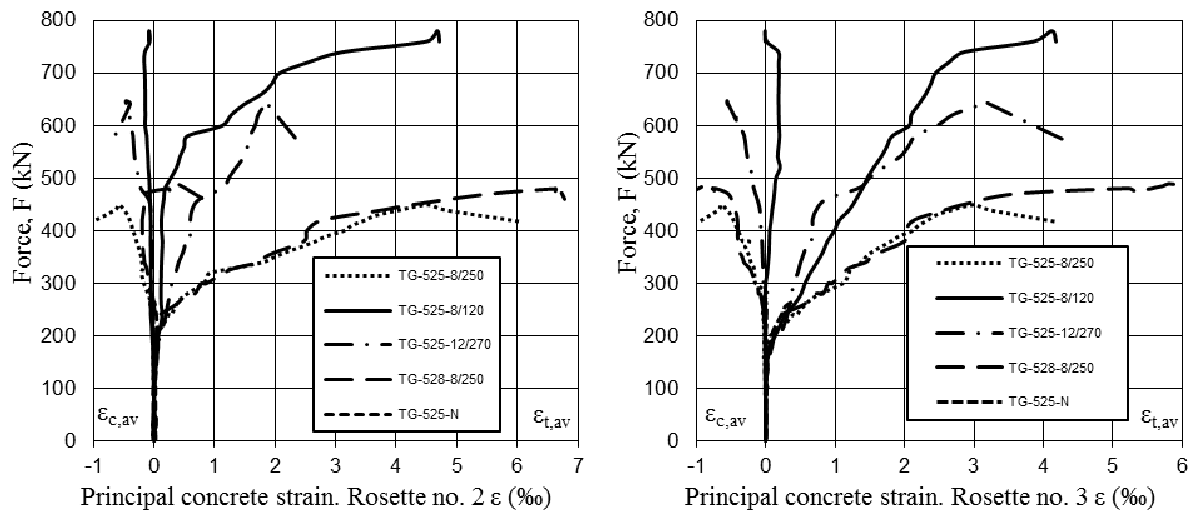

Fig. 6. Principal concrete strain, rosette no. 2 and no. 3.

In the beams with transverse reinforcement, two strain gauges were placed on every second stirrup in the analysed shear region (GFRP stirrups marked with crosses in Fig. 1). Figures 7 and 8 show the strains of GFRP stirrups registered by electric strain gauges. Figures show the strain values registered on the second GFRP stirrup from the left support, where the highest strain value of 0.011 was registered in beam TG-525-8/120. In the case of beam TG-525-12/270, the maximum strain value was observed on the first stirrup from the left support and it was equal to 0.0078 . In the other two beams, the maximum strain values were reached on the first stirrup from the left of the point load, with the maximum strain values of 0.0069 and 0.0108 registered for beams TG-525-8/250 and TG-528-8/250 respectively. The increase in the transverse reinforcement ratio caused an increase in the shear capacity of the beams and an increase in the strain values of the analysed stirrups. 
During the tensile tests of $8 \mathrm{~mm}$ and $12 \mathrm{~mm}$ diameter GFRP bars, the values of the ultimate tensile strain were higher than 0.018 . It should be noted that the maximum strain of the stirrups registered in the test was significantly higher than the design strain limit according to the existing codes $\left(\varepsilon_{\mathrm{vfrp}, \mathrm{lim}}=0.005\right.$ in CAN/CSA S806-12; $\varepsilon_{\mathrm{vfrp}, \mathrm{lim}}=0.004$ in ACI 440.1R-06 and CNR-DT 203/2006) [1-3].
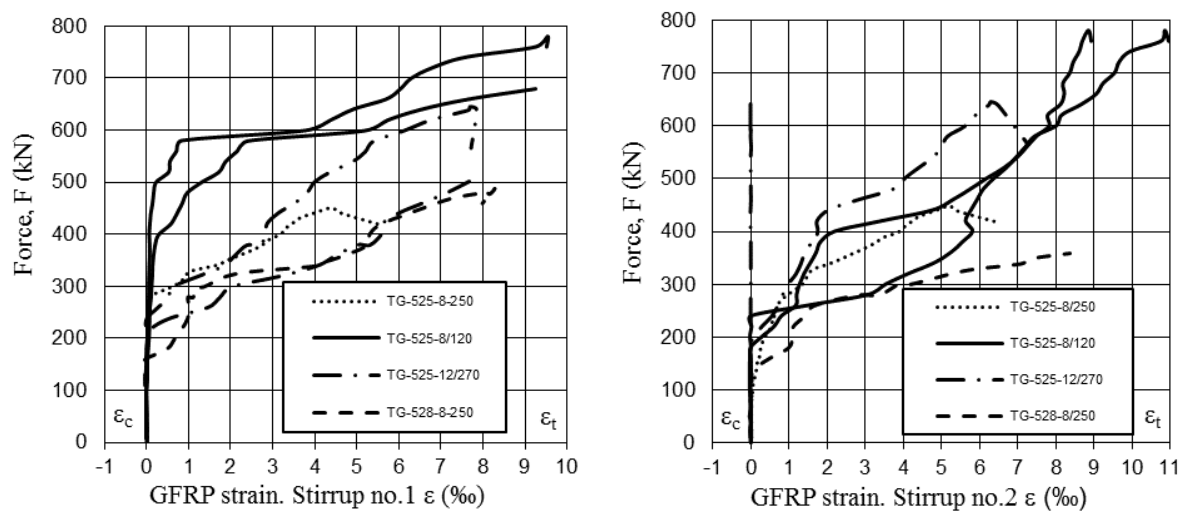

Fig. 7. Strain of GFRP stirrups.

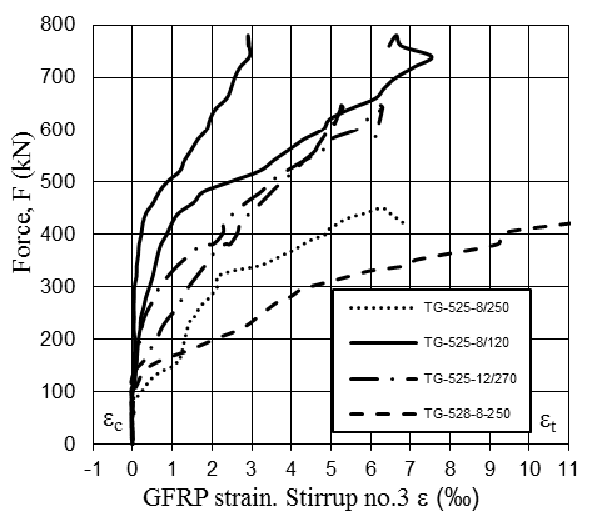

Fig. 8. Strain of GFRP stirrups.

Moreover, the increase in the transverse reinforcement ratio through the reduction of the stirrup spacing caused an increase in the stiffness of the beams, which was confirmed by significantly lower deflections. The increase in the shear reinforcement ratio from $0.16 \%$ to $0.33 \%$ caused a decrease in the maximum deflection under the point load equal to $10.0 \mathrm{~mm}$ and $6.6 \mathrm{~mm}$ respectively. The increase in the longitudinal reinforcement ratio from $2.91 \%$ to $3.61 \%$ resulted in the reduction of maximum deflection from $10.0 \mathrm{~mm}$ to $8.5 \mathrm{~mm}$.

\section{Conclusion}

The paper presents the results of experimental tests on the shear capacity of GFRP reinforced beams. The shear tests indicated promising results with regard to the effect of shear reinforcement ratio and longitudinal reinforcement ratio on the shear strength of GFRP reinforced concrete beams. The higher transverse reinforcement ratio was applied, the more cracks appeared, but with smaller opening width. The increase in the shear reinforcement ratio caused an increase in the shear strength of the beams and led to higher 
shear cracking load, which was confirmed by higher strain values of the GFRP stirrups. The increase in the longitudinal reinforcement ratio caused an increase in the shear capacity of the tested beams. Negative effects were observed for the larger spacing of stirrups with larger diameter compared to the smaller spacing of stirrups with smaller diameter and the same transverse reinforcement ratio. The increase in the transverse reinforcement ratio through the reduction of the stirrup spacing caused an increase in the stiffness of the beams. Similar shear failure mode occurred in all tested beams.

The authors gratefully acknowledge the FiReP International AG, which supplied the GFRP reinforcement for the experimental tests.

\section{References}

1. ACI Committee 440, Guide for the Design and Construction of Structural Concrete Rein-forced with FRP Bars, ACI 440.1R-06, no. May. ACI (American Concrete Institute), pp. 1-97. (2006).

2. CNR-DT 203/2006, Guide for design and construction of concrete structures reinforced with fiber-reinforced polymer bars. Rome, Italy, (2006).

3. CSA CAN/CSA S806-12 Design and construction of building components with fibre reinforced polymers. Toronto, Canada, (2012).

4. FIB Task Group 9.3 FRP reinforcement in RC structures, Bulletin No. 40. (2007).

5. T. Nagasaka, Hiroshi Fukuyama, and Masamaru Tanigaki. Shear performance of concrete beams reinforced with FRP stirrups. Special public. 138: 789-812 (1993).

6. S. Tottori, H. Wakui."Shear capacity of RC and PC beams using FRP reinforcement. Special Publication 138 615-632. (1993).

7. W. Zhao, K. Maruyama, and H. Suzuki. Shear behavior of concrete beams reinforced by FRP rods as longitudinal and shear reinforcement. RILEM PROCEEDINGS. CHAPMAN \& HALL, (1995).

8. J. Hegger, J. Niewels, M. Kurth. Shear analysis of concrete members with FiberReinforced Polymers (FRP) as internal reinforcement. FRPRCS-9, Australia, (2009).

9. A. K. El-Sayed, E. F. El-Salakawy, B. Benmokrane. Shear capacity of high-strength concrete beams reinforced with FRP bars. ACI Struct. J. 103, 3, (2006)

10. M. Said, M. Adam, A. Mahmoud, A. Shanour. Experimental and analytical shear evaluation of concrete beams reinforced with glass fiber reinforced polymers bars, Constr. and Buil. Mat. 102, Part 1, 574-591 (2016).

11. H. Nakamura, T. Higai. Evaluation of shear strength of concrete beams rein-forced with FRP. Doboku Gakkai Ronbunshu, 508, 89-100 (1995). 